\title{
Melucci e Tarrow: revisão teórica sobre movimentos sociais
}

\author{
Nayra Veras de Araujo* \\ Antônia Jesuíta de Lima**
}

\begin{abstract}
Resumo: O campo empírico que envolve os movimentos sociais é amplo e diversificado, o que resulta na existência de uma multiplicidade de modelos teóricos e abordagens diferentes para interpretá-los. Este fato deriva do esforço de alguns teóricos em tentar esclarecer o que são os movimentos sociais, quais seus fundamentos, como se formam, quais suas características, seus componentes entre outros traços que os definem e os compõem. O objetivo do artigo é discutir a contribuição teórica de Sidney Tarrow e Alberto Melucci para o estudo dos movimentos sociais. Tal intento deve ser compreendido como interesse em partilhar as contribuições dos autores supracitados para o estudo analítico dos movimentos sociais e evidenciar que, apesar de situados em paradigmas distintos, seus pressupostos teóricos não estão completamente desligados. O diálogo será traçado com vistas a oferecer o panorama teórico de análise de cada um dos autores: conceitos, categorias e abordagens.
\end{abstract}

Palavras-chave: Movimentos sociais; teoria social; identidade.

Abstract: The arena of social movements is wide and diversified, results in the existence of a multiplicity of theoretical models and different approaches. This fact derive from the efforts of some theorists to try clarify what are the social movements, what are your fundamentals, how formed, what are your features, your components and other traits that define e they make up the social movements. The purpose of this artice is to discuss on the theoretical contribution of Sidney Tarrow and Alberto Melucci for the study of social movements. This intent must be understood as an interest in sharing the contributions by these authors for the analytical study of social movements and evince that although located in different paradigms, your theoretical assumptions are not completely unconnected. The dialogue will be drawn in order to provide the panorama of theoretical analysis of each of the authors: concepts, categories and approaches.

Keywords: Social movements; teory social; identity.

\footnotetext{
* Graduada em História pela Universidade Estadual do Piauí. Mestranda em Políticas Públicas pela Universidade Federal do Piauí. Bolsista CAPES. Endereço postal: Universidade Federal do Piauí, Centro de Ciências Humanas e Letras, Campus Universitário Ministro Petrônio Portela, s/n, Ininga, Teresina, Piauí, CEP: 64049550. Endereço eletrônico: nayraveras@hotmail.com

** Graduada em Serviço Social pela Universidade Federal do Rio Grande do Norte. Mestre em Serviço Social e Doutora em Ciências Sociais pela Pontifícia Universidade Católica de São Paulo. Professora associada da Universidade Federal do Piauí. Endereço postal: Universidade Federal do Piauí, Centro de Ciências Humanas e Letras, Campus Universitário Ministro Petrônio Portela, s/n, Ininga, Teresina, Piauí, CEP: 64049550. Endereço eletrônico: a.jel@uol.com.br
} 


\section{Introdução}

A teorização dos movimentos sociais é uma preocupação recorrente nas Ciências Sociais, expressa em uma extensa produção, com escopos analíticos diversos. A recorrência dos estudos nessa área se impõe pela dinâmica mesma da sociedade, que vai requerendo novos modelos explicativos. Além disso, a complexidade do tema, a heterogeneidade de objetos e contextos são fatores que fazem dos movimentos sociais uma fonte quase inesgotável de estudos, análises e novos aportes analíticos.

Do modelo clássico, em que as mobilizações e os conflitos sociais foram interpretados à luz da teoria da revolução, às atuais interpretações, uma questão que move e reatualiza as análises diz respeito ao poder dos movimentos sociais nas sociedades, embora ganhem relevo também outras interrogações acerca de como e porque surgem os movimentos sociais, como eles se organizam, como se relacionam com a sociedade, instituições e atores políticos.

Para atender a gama de questões, na literatura especializada se encontram várias interpretações teóricas, ora privilegiando a importância do contexto econômico e político para o surgimento dos movimentos sociais, ora enfatizando as carências pessoais como fatores determinantes de motivação para a ação. O predomínio de um aspecto em uma determinada teoria não significa, necessariamente, o acerto de uma e o erro em outra. Na verdade, a diversidade de objetos empíricos que se inserem no rol dos movimentos sociais resulta, muitas vezes, em produções que não apresentam alcance teórico suficiente para explicar realidades específicas. Por outro lado, a supremacia de uma abordagem e, às vezes, a ausência de diálogo entre as teorias impede, muitas vezes, de se avançar na compreensão de determinados fenômenos sociais. Foi o que prevaleceu até a década de 1970 no âmbito da produção teórica dos movimentos sociais, com os desenvolvimentos paralelos das escolas norte-americana e europeia que, apesar das raízes empíricas comuns, seguiram rumos completamente diferentes (TONI, 2001), sem uma comunicação frutífera.

A partir da década de 1980, com as transformações econômicas e sociais das sociedades ocidentais, com a intensificação do processo de globalização e as mobilizações sociais assumindo contornos distintos das formas tradicionais, novos desafios analíticos vêm alterando significativamente a produção teórica sobre os movimentos sociais. Estudiosos, como Gohn (2000), Toni (2001) e Alonso (2009) vislumbram nos estudos, a partir dos anos 1990, tentativas de estabelecimento de diálogos e integração entre distintos enfoques teóricos. Identifica-se, conforme Alonso, esforços de

(...) sínteses conceituais e abordagens integradas, ambicionando conjugar o estudo das práticas de mobilização e dos códigos culturais que as orientam e focalizando experiências peculiares de produção de sentidos e identidades coletivas (2009, p. 71).

De fato, não obstante as polêmicas, críticas e confrontos, é possível notar aproximações analíticas, mesmo em campos teóricos distintos, o que sinaliza para essa tendência de integração. 
Entre os teóricos contemporâneos que se dedicaram aos estudos dos movimentos sociais, destacam-se Sidney Tarrow e Alberto Melucci, autores cuja obra iniciou-se na Itália, mas que floresceram em teorias distintas. Melucci leva o crédito de ser um dos fundadores do paradigma da identidade e Tarrow o crédito de realizar o trabalho mais abrangente na teoria do processo político, ambos forneceram instrumentais analíticos importantes para o desenvolvimento dessa temática. Aproximam-se suas proposições por se enquadrarem em teorias que contestam as explicações deterministas e economicistas da ação coletiva e a ideia de um sujeito histórico universal, pressuposto desenvolvido pela vertente marxista. Outro ponto em comum refere-se à associação que estabelecem entre a mudança social e as formas de conflito para desenvolverem suas análises.

O presente artigo visa explorar as conexões entre os pensamentos de Melucci e Tarrow, que não obstante estarem em paradigmas distintos: um no paradigma da identidade e outro no do processo político, têm, em suas formulações, pontos de contatos que os aproximam.

A motivação principal para essa reflexão responde a uma necessidade de melhor compreender as influências desses teóricos na produção sobre os movimentos sociais no Brasil, a partir da década de 1990. Além disso, levou-se em conta o fato de que, apesar da turbulência pela qual passou o campo dos movimentos sociais, com o abandono da temática por alguns estudiosos (como Castells e Habermas), Tarrow e Melucci sistematizaram seus trabalhos em grandes súmulas teóricas e passaram a ser referência no debate internacional.

É, portanto, sobre o diálogo entre esses dois teóricos que trata esse artigo. Tal intento deve ser compreendido como interesse em partilhar as contribuições dos autores supracitados para o estudo analítico dos movimentos sociais e evidenciar que, apesar de situados em paradigmas distintos, seus pressupostos teóricos não estão completamente desligados. Para tanto, o artigo está estruturado com essa introdução, uma caracterização dos modelos analíticos de Melucci e Tarrow e, por último, as aproximações e divergências de suas interpretações.

\section{Melucci e o Poder Simbólico dos Movimentos Sociais}

A produção teórica de Melucci sobre os movimentos sociais é a mais difundida e reconhecida entre o público internacional, porém "([...)] seria profundamente injusto reduzir o seu valor para um 'sociólogo dos movimentos sociais'(...)]" (CASQUETTE, 2001, p. 8. tradução nossa), pois suas abordagens tratam de temas diversos como epistemologia social, nacionalismo, globalização, democracia e cidadania, multiculturalismo, novas formas de desigualdade social e a condição juvenil.

Ainda assim, o nome de Melucci é sempre citado pelo crédito de ser um dos teóricos dos chamados novos movimentos sociais (NMS), corrente teórica que se difundiu na Europa a partir da década de 1980 fazendo a crítica ao paradigma tradicional marxista e ao utilitarismo da teoria da escolha racional. Os argumentos de Melucci se referem não só a reflexão do significado dos movimentos sociais na sociedade, pois é de seu interesse também explicar como deve se posicionar o pesquisador para a análise dos movimentos, ou seja, o autor dá indicativos metodológicos do "como fazer" pesquisa cujo objeto é movimentos sociais. 
Com Alain Touraine e Jürgen Habermas e outros estudiosos, Melucci propõe um novo esquema interpretativo de análise das sociedades complexas contemporâneas. Argumenta que o desenvolvimento capitalista não se sustenta mais no controle da força de trabalho e na transformação dos recursos naturais para o mercado, pois é cada vez mais crescente sua intervenção nas relações sociais, nos sistemas simbólicos, na identidade individual e nas necessidades. Destarte, há um deslocamento na origem dos conflitos sociais, do sistema econômico-industrial para as áreas culturais, do plano material para o plano simbólico. Os conflitos "(...) afetam a identidade pessoal, o tempo e o espaço na vida cotidiana, a motivação e os padrões culturais da ação individual" (MELUCCI, 1989, p. 58). A ênfase na cultura é atribuída pelo autor às transformações da sociedade na nova fase do capitalismo, em que prevalece a dominação simbólica através do consumo do discurso produzido e difundido pelos sistemas informacionais e simbólicos, entre os quais se sobressaem os meios de comunicação de massa.

Nas sociedades contemporâneas, em que a informação é o recurso fundamental, todos participam da produção de um campo simbólico e o poder age também como um elemento deste campo. Os profissionais da comunicação, as dinâmicas organizativas e os consumidores contribuem na produção do discurso público por meio das próprias competências, da autonomia das suas linguagens e da complexidade dos intercâmbios e das estratégias organizativas que o caracterizam. Os consumidores contribuem através da filtragem das mensagens, da ativação das redes afirmativas cotidianas, das escolhas do consumo que leva aos diversos meios. Nesta sociedade o acesso ao sentido torna-se o campo para novas formas de poder e conflito e o sentido da ação coletiva é, para Melucci, expressar o que está nascendo, anunciar as mudanças, "falar a frente". Dessa forma, o trabalho de análise desses conflitos é necessário para que se possa compreender o que estão a anunciar.

Melucci considera que "um movimento social é um objeto construído pela análise e não coincide com as formas empíricas de ação" (2001, p. 33). Quer afirmar, assim, que a simples existência do conflito não o qualifica como movimento social e que os fenômenos empíricos não têm significância imanente.

Uma ação coletiva não pode ser explicada sem levar em conta como os recursos internos e externos são mobilizados, como as estruturas organizacionais são constituídas e mantidas, como as funções de liderança são garantidas (1989, p. 56).

Melucci questiona os críticos da teoria dos "novos movimentos sociais" por eles situarem tais fenômenos no plano exclusivamente político, o que considera um viés por entender que a ação dos movimentos assume uma crescente autonomia dos sistemas políticos, estando "(...) estritamente entrelaçada com a vida cotidiana e com a experiência individual" (MELUCCI, 2001, p. 28). Mas, embora o autor reconheça a importância do enfoque político, o considera bastante limitado para explicar conflitos sociais contemporâneos, que afetam o sistema como um todo.

Melucci crítica as teorizações que se apoiam em generalizações empíricas, neste caso ele diz que a pesquisa sobre movimentos sociais não tem fugido do ve- 
\} MELUCCI E TARROW: REVISÃO TEÓRICA SOBRE MOVIMENTOS SOCIAIS - ARAUJO, N. V. e LIMA, A. J. \}

Iho dualismo sistema-atores. Ele identifica que a pesquisa empírica no campo da ação coletiva parte de três aspectos: 1) Interroga-se uma questão social; 2) Investigase as motivações do indivíduo; 3 ) Faz-se uma análise quantitativa dos eventos.

Partindo do entendimento de que o significado de uma ação coletiva depende de seu "sistema de referência" e de suas "dimensões analíticas", define um movimento social como "(...) uma forma de ação coletiva (a) baseada na solidariedade, (b) desenvolvendo um conflito, (c) rompendo os limites do sistema em que ocorre a ação (MELUCCl, 1989, p. 57).

Conflito, solidariedade e ruptura dos limites do sistema são, pois, as condições de existência de um movimento social. Estas dimensões, segundo ele, permitem diferenciar os movimentos sociais de outros fenômenos coletivos, como reivindicações organizadas e comportamento agregado de massa. Por solidariedade compreende "(...) a capacidade dos atores de se reconhecerem e serem reconhecidos como parte da mesma unidade social" (MELUCCl, 2001, p. 35). A noção de conflito, por sua vez, implica a luta de dois atores pela apropriação de recursos valorizados por ambos. A condição básica para que exista um conflito é a definição dos atores a partir de um sistema comum de referência e a existência de uma questão em disputa.

Melucci define como 'limites do sistema' a variabilidade dos estados sistêmicos, ou seja, as "(...) variáveis que em certo sistema pode tolerar sem modificar a própria estrutura" (2001, p. 37). O conceito de sistema, ao qual o autor se refere não deve ser confundido com os lugares concretos da prática social onde se situam empiricamente os movimentos sociais: instituições, associações e organizações. O sistema de referência, no seu modelo, deve ser compreendido como estruturas analíticas, como formas específicas de relações sociais.

Identifica, assim, três sistemas: o produtivo, no qual ocorre a produção de recursos constitutivos de uma sociedade, tanto a produção de bens econômicos, quanto à de bens culturais, simbólicos e cognitivos; o político, onde ocorrem as decisões referentes à distribuição dos recursos produzidos, tendo lugar nas organizações complexas, nos sistemas administrativos descentralizados etc. e o organizativo, que é responsável pela garantia do equilíbrio de uma sociedade e a sua adaptação ao ambiente através de processos de integração e de troca entre as partes do sistema.

Melucci classifica os movimentos sociais conforme a ruptura das regras internas de cada um desses sistemas. Antagonistas são os que provocam rupturas no sistema produtivo, políticos são os que provocam rupturas no sistema político e reivindicativos são os que agem no sistema organizativo. Apesar das distinções, são os movimentos antagonistas que ocupam grande espaço nas análises do autor, uma vez que para ele estes são conflitos em que os atores buscam preservar sua identidade e em que os objetivos são inegociáveis.

Recorre que a ação coletiva é um sistema de ação multipolar que combina orientações diversas, envolvendo atores múltiplos e implica um sistema de oportunidades e de vínculos que dá forma às suas relações. O processo de construção de um sistema de ação é o que Melucci (2001) vai chamar de identidade coletiva.

A identidade coletiva é, portanto, uma definição construída e negociada pela ativação das relações sociais entre os atores. 
Implica a presença de quadros cognitivos, de densas interações e também das dimensões efetivas e emocionais (MELUCCI, 2001, p. 158).

A identidade coletiva é aquilo que une os indivíduos em um nós. E como um nós se transforma em nós é a questão de pesquisa colocada por Melucci no âmbito dos movimentos sociais. A identidade coletiva não é um dado ou uma essência, mas um produto de trocas de negociações, decisões, conflitos entre os atores. Processos de mobilização, formas organizativas, modelos de lideranças, ideologias e formas de comunicação são níveis de análise significativos para reconstruir internamente o sistema de ação que constitui o ator coletivo. Mas, também as relações com os concorrentes, aliados, adversários e, em particular, as respostas dos sistemas políticos e dos aparatos de controle social, que definem um campo de oportunidades e vínculos dentro do qual um ator coletivo se forma, se mantém ou se modifica no tempo (MELUCCI, 2001).

É à luz desses postulados teóricos que Melucci desenvolve sua análise sobre os movimentos sociais nas sociedades complexas, que, segundo ele, não são mais organizados em torno do conceito de classe social.

Para Melucci não existem "atores conflituais" por essência, a ação tem manifestações temporárias, pode envolver atores diversos, pode deslocar-se em áreas diversas do sistema. Além disso, as reflexões de Melucci levam as seguintes conclusões: primeiro, o autor idealiza o fim dos atores-personagens e concebe a transferência de atenção para os processos de construção da ação social. Melucci conclui que o fim dos atores personagens nos leva "a transferir a atenção para os processos de construção da ação social" (2001, p. 166), o que aponta a necessidade de definir a ação humana como construção de possibilidades no interior de limites do sistema. A tensão entre limite/possibilidades revela a precariedade de uma realidade baseada na racionalidade e no cálculo entre meios e fins, abrindo espaço para as emoções, intuições e criatividade entrarem no processo de construção de nossa realidade individual e social.

Melucci conclui ainda que a ação social é pensada como uma significação, colocando fim ao dualismo estruturas-intenções. A ação é pensada como um processo interativo de construção no interior de um campo de possibilidades de limites que os atores reconhecem. Sendo a ação um processo de construção, também o conhecimento entra no processo de construção como uma forma particular de ação social dotada de um grau de autorreflexividade. Segundo ele, trata-se de redefinir a relação entre observador e observado.

Melucci se afasta de interpretações conjunturais e estruturais. Desconsidera a visão de que movimentos sociais sejam personagens, isto é, que sejam compreendidos como uma estrutura definida e homogênea. Ao contrário disso, concebeos como fenômenos heterogêneos e fragmentados, que destinam muitos recursos para gerir a complexidade e a diferenciação que os constitui. Critica também a postura que considera os movimentos como efeitos de uma situação histórica ou produtos de uma determinada conjuntura, sem levar em conta as motivações, o sentido e os componentes da ação coletiva. Por outro lado, considera que as 
\} MELUCCI E TARROW: REVISÃO TEÓRICA SOBRE MOVIMENTOS SOCIAIS - ARAUJO, N. V. e LIMA, A. J. \}

motivações, os atores e as diferenças individuais não são suficientes para explicar como ocorre que certos indivíduos se reconheçam e se tornem parte de um nós. (MELUCCl, 2001). Desconsidera ainda que os movimentos sociais sejam resultados de crises econômicas ou de contradições do sistema.

Melucci privilegia uma abordagem micro, ou seja, centrada na postura dos indivíduos ante a ação coletiva. Admite que fatores externos possam contribuir para o surgimento dos movimentos sociais, mas ressalta a postura dos atores como elemento nuclear na ação coletiva.

(...) ao emergir de ações concretas, contribuem fatores facilitadores de tipo conjuntural (como, por exemplo, a estrutura de oportunidades políticas, a existência de empreendedores, o grau de equilíbrio ou crise do ambiente etc.). Mas esses fatores não poderiam operar se o ator não tivesse a capacidade de percebê-los e integrá-los em um sistema de orientação que constitui a estrutura condutora da sua ação (MELUCCI, 2001, p. 47).

Isto significa que Melucci não ignora a importância de fatores externos para a ação coletiva, porém tais fatores não têm centralidade na sua análise. A existência de fatores externos só facilita a ação coletiva porque os atores são capazes de perceber suas contribuições para o movimento. Ao se concentrar nos atores, destaca a importância da motivação para a ação coletiva, mas essa não deve ser compreendida como uma variável exclusivamente individual, pois sobre ela influi, de maneira determinante, a estrutura de incentivos das redes de relação (MELUCCI, 2001).

\section{O Poder em Movimento:}

\section{contribuições de Tarrow ao estudo dos movimentos sociais}

O nome de Tarrow inclui-se na teoria hoje conhecida como teoria do processo político (TPP), corrente teórica que surgiu nos anos 1980 fruto do debate entre a teoria americana da mobilização de recursos (TMR) e a corrente europeia dos novos movimentos e se desenvolveu na América. Ao contrário da teoria da mobilização de recursos, que se apoia numa lógica utilitarista de atores individuais e das elites, o modelo do processo político "(...) se preocupa mais com as interações estratégicas entre os movimentos sociais e o ambiente onde operam e enfatiza o contexto político e social" (TONI, 2001, p. 86). Uma questão central dessa abordagem é saber por que surgem as mobilizações políticas. Descartando o psicologismo que norteou as primeiras correntes norte-americanas, especialmente a da Escola de Chicago, essa teoria recoloca a importância das mudanças estruturais da sociedade para a explicação das mobilizações coletivas.

Entre os principais teóricos do processo político estão autores que já haviam produzido para a teoria da mobilização de recursos, que reformularam ou ampliaram suas abordagens inserindo-se na nova teoria, é o caso de Tilly, McAdams, Snow e Benford, Obershall, Della Porta e McCarthy, Traugott. E outros cujos nomes estão exclusivamente ligados a nova teoria, como: Klandermas, Friedman, Traugott, 
\} MELUCCI E TARROW: REVISÃO TEÓRICA SOBRE MOVIMENTOS SOCIAIS - ARAUJO, N. V. e LIMA, A. J. \}

Fantasia, Muller e Tarrow. A construção teórica deste último é o objeto da discussão que iniciamos neste tópico.

A obra Power in Movement (1994), publicada no Brasil com o título Poder em Movimento (2009), consagra Tarrow como um dos principais teóricos dos movimentos sociais nos anos de 1990, "influenciando no início do século XXI vários analistas do Brasil e da Argentina na análise das ações coletivas locais" (GOHN, 2008 , p. 33). Nesta obra, o autor tenta identificar os processos que geram os confrontos e como a interseção desses processos com os tipos de mobilização, oportunidades e identidades criam movimentos sociais e grandes ciclos de confronto. Sua proposta é oferecer um amplo quadro teórico para entender o lugar dos movimentos sociais, dos ciclos de confronto e das revoluções na categoria mais geral do confronto político.

Na construção teórica de Tarrow, confronto é o termo para se referir à ação coletiva empregada por pessoas que, por não terem acesso regular às instituições, desafiam os outros ou as autoridades em nome de novas exigências ou reivindicações não atendidas (TARROW, 2001). O confronto é o ponto de convergência entre todos os movimentos sociais, protestos e revoluções a ação coletiva de confronto. A questão que guia sua construção teórica é saber o que ocasiona o surgimento de um confronto. $\mathrm{O}$ autor lembra que algumas explicações teóricas para essa questão foram de ordem psicológica, expressão da mentalidade da multidão, da anomia e da privação. Explicações dadas pela tradição social-psicológica da escola de Chicago, que prega que "(...) tensões sociais causam mudanças psicológicas e induzem o ser humano ao comportamento anormal" (TONI, 2001, p. 80). Contrapondo-se a essa visão, Tarrow considera que privações não são fatores suficientes para o surgimento de confrontos, pois esta é uma condição que pode ser permanente, independente da existência de confrontos. Assim, se privações existem quando não há confrontos, como elas podem ser as responsáveis pela existência daqueles?

Tarrow argumenta que, se carências e privações são dados constantes, o motivo que gera os confrontos são as mudanças de oportunidades, que são, para ele, dados variáveis. O autor afirma que o confronto é mais relacionado às oportunidades e restrições à ação coletiva do que a fatores sociais ou econômicos permanentes vivenciados pelas pessoas. "O que varia muito no tempo e no espaço são os níveis e os tipos de oportunidades com que as pessoas se deparam, as restrições em suas liberdades de ação e a percepção de ameaças a seus interesses e ações (TARROW, 2009, p. 99). Compreender a estrutura de oportunidades políticas é primazia na interpretação teórica Tarrow.

A importância conferida à noção de oportunidades políticas é o aspecto que o insere numa teoria do processo político, "(...) a TPP prioriza uma estrutura de incentivos e/ou constrangimentos políticos, que delimita as possibilidades de escolha dos agentes entre os cursos da ação" (ALONSO, 2009, p. 56). Oportunidades políticas são "(...) dimensões sólidas da luta política que motivam as pessoas a se engajar no confronto político" (TARROW, 2009, p. 39), fornecem incentivos para a ação coletiva ao afetarem as expectativas das pessoas quanto ao sucesso ou fracasso e não são necessariamente formais, permanentes ou racionais. Isto implica dizer que não há uma fórmula para presumir a origem de um confronto, pois estas variáveis 
\} MELUCCI E TARROW: REVISÃO TEÓRICA SOBRE MOVIMENTOS SOCIAIS - ARAUJO, N. V. e LIMA, A. J. \}

mudam em diferentes circunstâncias históricas e políticas. A "estrutura de oportunidades políticas" representa, assim, um conjunto de indícios de quando surgirá um confronto político.

Tarrow estabelece cinco dimensões das oportunidades que ajudam a moldar os movimentos. São elas: o acesso institucional, que corresponde à abertura do acesso à participação para os novos atores, ele explica que "(...) quanto mais estreitos os caminhos já existentes para a participação, mais provável se torna que cada nova abertura produza novas oportunidades de confronto" (TARROW, 2009, p. 107); realinhamentos políticos no interior do sistema; aparecimento de aliados influentes, quando aparecem aliados os desafiantes são encorajados à ação coletiva; divisões no interior da elite, é uma variável importante porque, além de incentivar os grupos com poucos recursos a assumirem os riscos da ação coletiva, encoraja os segmentos da elite que estão fora do poder a assumirem o papel de "defensores do povo" (TARROW, 2009, p. 108) e por último o declínio na capacidade do Estado de reprimir a dissidência. Tarrow adverte que algumas vezes, as oportunidades políticas ocorrem para certos grupos e não para outros, mas, apesar dessas variações, os movimentos surgem porque variações nas condições de mobilização cresceram no sistema político em geral.

O termo movimentos sociais, na abordagem do autor, é reservado para designar as sequências de confronto político baseadas em redes sociais de apoio e em vigorosos esquemas de ação coletiva que, desenvolvem a capacidade de manter provocações sustentadas contra opositores poderosos. Em outros termos,

(...) as pessoas se engajam em confrontos políticos quando mudam os padrões de oportunidades e restrições políticas e, então, empregando estrategicamente um repertório de ação coletiva, criam novas oportunidades que são engendradas por outros, em ciclos mais amplos de confronto. Quando suas lutas giram em torno de grandes divisões da sociedade, quando reúnem pessoas em volta de símbolos culturais herdados e quando podem ampliar ou construir densas redes sociais e estruturas conectivas, então esse episódios de confronto resultam em interações sustentadas com opositores - especificamente, em movimentos sociais (TARROW, 2009, p. 38, grifo nosso).

Alguns esclarecimentos precisam ser feitos para a compreensão deste modelo, a começar pela definição do conceito de repertório. Repertório é uma categoria que Tarrow absorve de Tilly e que remete a descrição das práticas da ação coletiva. Diz respeito ao conjunto de práticas da ação coletiva em defesa de interesses comuns, em suas palavras, "(...) é um conceito ao mesmo tempo estrutural e cultural, envolvendo não apenas o que as pessoas fazem quando estão engajadas num conflito com outros, mas o que elas sabem sobre como fazer e o que os outros esperam que a façam" (TARROW, 2009, p. 51). Repertório é o termo usado para definir as formas de ação de um movimento social, mas por se constituir de variáveis, os confrontos não seguem o mesmo repertório, resultam do aprendizado cultural dos desafiantes, 
que, através de interações, deliberam sobre as ações que podem oferecer maior possibilidade de sucesso na ação coletiva de confronto.

Quais seriam as formas de ação e como elas podem influenciar no sucesso de um movimento? Como podem interferir na luta pela conquista dos interesses coletivos? Qual o potencial dessas formas de confronto para o movimento social?

Tarrow responde dizendo que o repertório de confronto oferece três tipos básicos de ação coletiva: violência, ruptura e convenção. Cada uma apresenta vantagens e desvantagens.

Contrariando a visão de que a violência é expressão da disfunção psicológica ou social, Tarrow a concebe como uma função interativa entre as táticas dos que protestam e o policiamento. Para Tarrow (2009) a ameaça de violência tem um grande poder nos movimentos, mas tem a desvantagem de proporcionar às autoridades pretextos para repressão, além de restringir e assustar simpatizantes. A ação convencional por sua vez, se refere à forma de ação coletiva que exige pouco compromisso, baixo risco e atrai grande número de participantes. Estes são os maiores atrativos das formas convencionais, por serem simples de ser empregadas e a forma de ação coletiva predominante, são exemplos a greve e a demonstração. A vantagem da convenção é criar rotina que as pessoas entendem e que as elites irão aceitar ou até facilitar. A terceira forma, a ruptura, é fonte de grande parte da inovação no repertório e do poder em movimento, pois quebra a rotina, espanta espectadores e deixa elites desorientadas. Porém tem a desvantagem de ser mais instável e facilmente gera violência.

Mas o potencial de um confronto não está apenas no repertório utilizado, há que se considerar ainda o poder simbólico das suas ações. Tarrow fala que tentativas de mobilização simbólica acompanham todos os movimentos sociais modernos e que maioria dos estudiosos concorda que os significados são construídos. Disso Tarrow não discorda, mas argumenta que a luta entre os movimentos e seus opositores não é meramente cognitiva e simbólica, como prega Melucci, por exemplo. Sua preocupação concentra-se em analisar como os discursos simbólicos tomam forma no processo de luta, pois ainda que considerasse que o conteúdo básico de um movimento é seu simbolismo, Tarrow se questiona sobre como a mensagem de um confronto é recebida e interpretada, no tempo e no espaço, por diferentes sujeitos sociais. Seguindo a trilha de outros estudiosos dos movimentos sociais tais como Klandermans e Snow, Tarrow concebe o conceito de quadros interpretativos para compreender a natureza interativa dos movimentos sociais.

Em anos recentes estudiosos dos movimentos sociais começaram a usar termos como quadros interpretativos, pacotes ideológicos e discursos culturais para descrever os significados compartilhados que inspiram as pessoas a participarem de uma ação coletiva. Esses termos são usados em substituição à expressão original frames.

Os frames são mecanismos que ressaltam, enfatizam e acentuam a gravidade e a injustiça de uma condição social. Os quadros interpretativos (frames) permitem o envio de uma mensagem uniforme para os detentores do poder e outros.

Um confronto pode apresentar um descontentamento, identificar um público e indicar um inimigo. A adoção coletiva de um quadro interpretativo precisa ser 
\} MELUCCI E TARROW: REVISÃO TEÓRICA SOBRE MOVIMENTOS SOCIAIS - ARAUJO, N. V. e LIMA, A. J. \}

publicamente compartilhada, e os movimentos sociais são os responsáveis por esse processo. Os movimentos tentam anunciar as reivindicações em termos de quadros de significados compreensíveis para uma sociedade e para isso, "usam formas de ação coletiva extraídas de um repertório existente e desenvolvem tipos de organização que frequentemente imitam as organizações as quais se opõem" (TARROW, 2009, p. 45).

Contudo, o autor alerta que os símbolos culturais não estão automaticamente disponíveis como símbolos mobilizadores, mas exigem agentes concretos para transformá-los em quadros interpretativos de confronto. Os agentes concretos a que ele se refere são os líderes, que têm a importante função de selecionar formas de ação coletiva: os líderes inventam, adaptam e combinam várias formas de confronto para ganhar apoio de pessoas, eles "(...) orientam os quadros interpretativos de seus movimentos para a ação em contextos particulares e os amoldam à interseção entre um alvo da cultura da população e seus próprios valores e objetivos" (TARROW, 2009, p. 144).

É necessário atentar que nem todos os processos de enquadramento interpretativo ocorrem sob o controle dos líderes, pois, além de trabalhar com entendimentos culturais herdados, os líderes competem com a mídia, que transmite mensagens que os movimentos devem moldar e influenciar. Quadros culturais existentes e a mídia são mecanismos que restringem a formação dos movimentos. A mídia interfere à medida que tende a focalizar o que é notícia, "os movimentos são afetados pela preferência da mídia por eventos dramáticos e visíveis" (TARROW, 2009, p. 151). Tarrow diz que o trabalho de enquadramento é principalmente cognitivo e avaliador, identificando descontentamentos e os traduzindo em reivindicações mais amplas dirigidas a outros que seja significativo.

A cultura da ação coletiva é feita de quadros interpretativos e de emoções que visam tirar as pessoas de sua submissão, mobilizando-as para a ação em cenários conflituosos, Os símbolos são extraídos seletivamente de um reservatório cultural pelos líderes do movimento e combinados a crenças orientadas para a ação, de modo a navegar estrategicamente em meio a um paralelogramo de atores, que vai desde estados e oponentes na sociedade até militantes e populações-alvo. O mais importante é que a eles é dada uma valência emocional que visa converter a passividade em ação (TARROW, 2009, p. 146).

Tarrow entende que a cultura sob dois aspectos, primeiro como sistemas de significados usados pelas pessoas cotidianamente e, segundo, como a base da identidade social e política. O autor se questiona como as identidades existentes restringem ou fortalecem os movimentos e como novas identidades são formadas no processo de confronto. Ele responde a essa questão destacando sobre cinco aspectos: primeiro, ele considera que identidades "naturais" ou "herdadas" são quase sempre a base de agregação em movimentos sociais; segundo, os movimentos sociais ne- 
\} MELUCCI E TARROW: REVISÃO TEÓRICA SOBRE MOVIMENTOS SOCIAIS - ARAUJO, N. V. e LIMA, A. J. \}

cessitam de solidariedade para agir de forma coletiva e consistente e criar ou ter acesso a identidades em torno de suas reivindicações é uma maneira de fazê-lo; terceiro, a solidariedade dos seus militantes é quase sempre baseada em comunidades mais íntimas e especializada: como as "comunidades de discurso"; quarto, construir um movimento em torno de fortes laços de identidade coletiva poupa o trabalho da organização e, finalmente, não deveríamos considerar a identidade coletiva de um movimento social como permanente ou impermeável à influência externa. Assim como seus repertórios de confronto, as identidades não são simplesmente feitas a partir do nada, mas respondem às mudanças nas oportunidades e nas restrições políticas, nas necessidades estratégicas e nos materiais culturais disponíveis (TARROW, 2009).

Os movimentos sociais são, no modelo de Tarrow, responsáveis por formar organizações, elaborar ideologias, socializar e mobilizar seus membros, estes se engajam em autodesenvolvimento e na construção de identidades coletivas.

[...] as formas de ação coletiva têm poder porque desafiam os detentores de poder, produzem solidariedade e fazem sentido para grupos específicos da população, situações e culturas nacionais (TARROW, 2009, p. 20).

O autor diz que o confronto político está culturalmente inscrito e socialmente comunicado, ou seja, ele não se origina na cabeça dos organizadores, ele surge em decorrência das circunstâncias externas ao movimento e das relações que se estabelecem entre seus participantes. Com isso, Tarrow enfatiza a importância dos líderes para a ação coletiva de confronto.

Ao argumentar sobre os ciclos de confronto, o autor diz que os choques entre os desafiantes iniciais e as autoridades revelam os pontos fracos dos últimos e as forças dos primeiros. Uma vez deflagrados, geralmente por uma situação de ampliação de oportunidades, a informação extravasa e o aprendizado político se acelera.

\section{Aproximações e Divergências entre Tarrow e Melucci}

Na década de 1980, a discussão teórica sobre movimentos sociais foi marcada por enorme polêmica, forte debate e pouca conciliação o que resultou em dificuldades de aproximações entre as teorias existentes, que ficaram restritas à aplicação em realidades especificas. Na década seguinte, principalmente na América Latina, os estudos seguiram a trilha dos estudos sobre a sociedade civil, revelando um deslocamento de atenção dos movimentos para a sociedade civil. Nos últimos anos, os estudos têm se concentrado em aproximações conceituais que permitam compreender dimensões estratégicas e simbólicas, explicar a construção de identidades coletivas e diagnosticar os incentivos e constrangimentos sociopolíticos à mobilização. Este esforço de síntese e aproximação, entretanto, deixa margem para dúvidas quanto as possibilidade de aproximação, principalmente quando se trata de paradigmas teóricos divergentes e até opostos, como no caso dos autores trabalhados neste artigo. 
\} MELUCCI E TARROW: REVISÃO TEÓRICA SOBRE MOVIMENTOS SOCIAIS - ARAUJO, N. V. e LIMA, A. J. \}

Os autores trabalhados neste artigo são marcados pela divergência de enfoque teórico-metodológico: micro versus macro, política versus cultura, objetividade versus subjetividade etc. Ante as divergências, por que então podemos supor que há alguma possibilidade de aproximação entre ambos?

A resposta está na entrelinha dos argumentos de ambos os autores, pois se é verdade, tal qual argumentou Melucci, que os movimentos são heterogêneos e o trabalho de análise depende da decomposição do movimento, pois cada realidade abriga significados múltiplos, é verdade também, que cenários históricos e institucionais específicos devem ser observados, tal qual argumentou Tarrow.

O que está no plano de frente de um autor é o que está no plano de fundo do outro, mas acreditamos que mesmo em planos diferentes é a existência desses conceitos que permite a aproximação entre um e outro. Nas sociedades contemporâneas em que o global e local estão imbricados, não se pode estabelecer que os conflitos sejam apenas culturais e simbólicos. Na diversidade de interesses que hoje perpassa as relações humanas, o poder sai da esfera estatal para a esfera cotidiana das relações pessoais e este fato não deve ser desconsiderado das análises acadêmicas. Acreditamos que os conflitos são resultados sim de disputa de poder simbólico, mas não somente este, pois os poderes político e econômico também fazem parte de nossas relações. Os movimentos sociais não foram engolidos pelo engodo da sociedade civil, eles estão mais vivos do que nunca e ultrapassaram as fronteira do Estado nacional e ampliam-se pela transnacionalidade do mundo global.

Os autores citados partem do mesmo problema, encontrar um suporte teórico para análise dos movimentos sociais, porém partem de princípios diferentes. Melucci identifica nas generalizações empíricas o principal problema das teorias existentes, que, segundo ele, não conseguem fornecer instrumental analítico adequado para a compreensão dos movimentos sociais. Para Tarrow “(...) os estudiosos se concentram em teorias especificas ou em alguns aspectos do movimento em detrimento de outros" (2009, p. 19), por isso considera que se precisa de um quadro mais amplo para poder relacionar os movimentos sociais. Com argumentos opostos, estes autores, entretanto, propõem-se a criar um substrato teórico que permita trabalhar analiticamente o fenômeno dos movimentos sociais. Gohn (2001) inclui o nome desses autores no grupo dos que persistiram no estudo dos movimentos sociais, mesmo depois da onda de pessimismo que se abateu entre alguns teóricos que se redefiniram para atender a ordem de um mundo globalizado, a exemplo de Touraine e Habermas e Castells.

Melucci (1989) destaca a contribuição de Tarrow para a interpretação analítica dos movimentos sociais, ele diz que o esforço de teorização a que muitos autores se dedicaram, concentrou-se mais em definições empíricas do que em conceitos analíticos, mas destaca o nome de Tarrow como importante por ter feito uma distinção entre movimentos, organizações de protesto e eventos de protesto. Diz ele que "por não ser meramente descritiva, esta é uma distinção que serve para evitar a confusão entre os vários fatores" (MELUCCI, 1989, p. 55), embora considere que esta distinção também não basta.

Pelo exposto nos tópicos anteriores, é possível detectar que estes autores partem de análises diferenciadas, Tarrow se concentra na análise dos fatores externos 
ao passo que Melucci se concentra nos determinantes internos; este enfatiza o aspecto cultural, aquele se volta para o aspecto político. Esta distinção traduz a forma como esses autores olham para os movimentos. Tarrow se apoia numa ótica externa. Para este autor os movimentos sociais dependem do meio externo, especialmente das oportunidades políticas, para coordenar e sustentar sua análise. Na sua análise os movimentos sociais são resultados mais de oportunidades favoráveis que da ação dos indivíduos. Melucci, por sua vez, embora não ignore a importância das oportunidades, se atém à abordagem micro, ou seja, na ação coletiva de indivíduos.

Apesar das diferenças analíticas, alguns termos se revelam comuns nos dois autores, como os conceitos de identidade, quadros cognitivos e aspectos relacionados à organização do movimento. O conceito de estruturas de oportunidades políticas é categoria básica no modelo de Tarrow, mas não é completamente ignorada por Melucci. Há uma inversão de prioridades, para Tarrow as oportunidades são os elementos fundamentais para justificar o surgimento de confrontos, Melucci prioriza a ação dos indivíduos, mas considera que estruturas de oportunidades políticas é um conceito relevante para a análise da ação coletiva.

\begin{abstract}
A ação coletiva de um movimento é resultante de objetivos, recursos e limites, isto é, uma orientação finalizada que se constrói por meio de relações sociais no interior de um campo de oportunidades e de vínculos. Os atores constroem a sua ação através de investimentos organizados: definem, isto é, em termos cognitivos, o campo das possibilidades e dos limites que percebem, ativando ao mesmo tempo suas relações para dar sentido ao seu agir comum e aos objetivos que perseguem (MELUCCI, 2001, p. 46).
\end{abstract}

Este aspecto evidencia o que foi dito agora há pouco sobre planos diferentes. As oportunidades estão no plano de frente de Tarrow e no plano de fundo de Melucci, mas elas existem para ambos e este fato evidencia o contato entre ambos. Dessa forma a análise de um movimento não deve ignorar este fator. Não pensamos que ela tenha maior ou menor importância ante o poder simbólico. Em nosso entendimento ambos abrigam o mesmo grau de importância.

Da mesma forma, Tarrow não ignora o elemento identidade, funda-se no argumento que "(...) a coordenação da ação depende da confiança e da cooperação gerada entre os participantes por meio de entendimentos e identidades compartilhados" (TARROW, 2009, p. 40). O autor vai dizer que os movimentos utilizam identidades coletivas e moldam novas identidades ao formularem suas mensagens ideológicas e ao projetarem seus inimigos e aliados (TARROW, 2009). Mas, apesar de não desconsiderar o fator identidade, quando se trata de poder simbólico os movimentos ficam em desvantagem quando competem com os estados.

Melucci dá a identidade coletiva uma definição interativa e compartilhada, ou seja, construída e negociada através de um processo repetido de ativação das relações que ligam os atores. A identidade coletiva resulta de um processo de cons- 
\} MELUCCI E TARROW: REVISÃO TEÓRICA SOBRE MOVIMENTOS SOCIAIS - ARAUJO, N. V. e LIMA, A. J. \}

trução, manutenção e adaptação que para Melucci se compõe de dois eixos, a complexidade interna de um ator e as orientações que o caracterizam; e a sua relação com o ambiente (outros atores, oportunidades/vínculos). Este processo é a base para a construção das expectativas e para o cálculo dos custos e benefícios da ação.

A construção de uma identidade coletiva implica investimentos contínuos e ocorre como um processo: a identidade pode tanto mais cristalizar-se em formas organizativas, sistemas de regras, relações de leadership quanto mais nos aproximamos das formas mais institucionalizadas do agir social. Na ação coletiva ela tem prevalentemente o caráter de um processo que deve ser continuamente ativado para tornar possível a ação. (MELUCCl, 2001, p. 69)

Tarrow recorre às percepções dos culturalistas em alguns aspectos como o conceito de repertório, à noção de enquadramento interpretativo, à atenção dada à identidade coletiva e a difusão durante os ciclos. Mas recua diante do engodo de se interpretar todos os confrontos como lutas por significados. Tarrow focaliza os eventos que tornam o significado manifesto, afirma que a cultura precisa estar inserida na mudança cultural, ele tenta mostrar como oportunidades políticas provocam respostas discursivas e centra sua atenção no que as pessoas escolhem fazer quando agem coletivamente. 


\section{Referências Bibliográficas}

ALONSO, Angela. As teorias dos movimentos sociais: um balanço do debate. Lua Nova, n. 76. São Paulo: Cedec, 2009. p. 87-118

CASQUETTE, Jesús. In memoriam Alberto Melucci (1943-2001). REIS, Revista Espanhola de Investigações Sociológicas, n. 96, out.-dez. Madri, s/ed., 2001. $\mathrm{GOHN}$, Maria da G. Novas teorias dos movimentos sociais. São Paulo: Ed. Loyola, 2008.

. Teoria dos movimentos sociais: paradigmas clássicos e contemporâneos. 2a. ed. São Paulo: Ed. Loyola, 2000.

MELUCCI, Alberto. A invenção do presente: movimentos sociais nas sociedades complexas. Petrópolis, Rio de Janeiro: Vozes, 2001. Um objeto para os movimentos Sociais. Lua Nova, n. 17, junho. São Paulo: Cedec, 1989. p. 50-66.

TARROW, Sidney. O poder em movimento: movimentos sociais e confronto político. Petrópolis: Vozes, 2009.

TONI, Fabiano. Novos rumos e possibilidades para o estudo dos movimentos sociais. BIB, n. 52, 2o. semestre. São Paulo: Anpocs, 2001. p. 79-104.

Recebido em 08 de março de 2010.

Aprovado para publicação em 22 de junho de 2010. 